\title{
Aspectos éticos da terapia sexual
}

Nelson Vitiello*

\section{1 - INTRODUÇÃO. CONCEITOS.}

Para que bem possamos situar o problema, é necessária uma clara compreensão dos conceitos de leis, costumes, moral e ética.

Desde que os primeiros hominídeos começaram a se juntar em famílias, bandos e tribos - o que acabou dando origem aos conceitos de nações, povos e países - ficou clara a importância da instituição de normas de comportamento que regessem o relacionamento entre as pessoas. De início, tais normas foram fundamentadas na "Lei do mais forte" que, infelizmente, ainda rege muitos dos aspectos das culturas humanas. Com a evolução da consciência social, essas regras foram evoluindo, no sentido de dar maior e mais eficiente proteção aos menos favorecidos.

O relacionamento dos indivíduos entre si, adaptados a um determinado meio ambiente, foi aos poucos dando origem à hábitos que, ao se consolidarem entre esses indivíduos resultou, ao longo de gerações, no que denominamos de "costumes". Assim, os conceitos do que é certo ou errado num relacionamento foram aos poucos sendo definidos de acordo com o que os

* Ginecologista e Terapeuta Sexual. Doutor em Medicina. Presidente da SBRASH. 
costumes determinavam. Os costumes foram se cristalizando no que denominamos de "moral". Essa palavra deriva do latim morale, isto é, relativo aos costumes.

Moral, portanto, é o conjunto de regras de conduta consideradas como válidas por uma determinada sociedade, em uma determinada época.

Fica implícito em tal conceito ser a moral variável para cada cultura (ou mesmo para cada segmento dessa cultura) e para cada época. O que é considerado moral em determinado segmento cultural numa determinada época pode não sê-lo em outro segmento ou em época diversa. Para ficarmos apenas com um exemplo, podemos considerar que a escravidão fez parte dos costumes de nossa cultura ocidental cristã até muito recentemente, não tendo, em tais épocas, nada de atentatório à moral. Mesmo instituições que se arvoram de defensoras dos costumes e da moral, como a Igreja Católica, por exemplo, nada via de errado na escravidão, sendo costumeiro que mesmo os sacerdotes católicos tivessem escravos. Nesse aspecto, a escravidão foi "moral" entre nós até pouco mais de um século.

A reboque dos costumes, as sociedades estruturadas sempre traçaram dispositivos legais, que regiam de forma clara os direitos e os deveres dos cidadãos. Em nossa cultura, desde as célebres "Leis das Doze Táboas", o código legal mais primitivo na antiga Roma, sempre fomos regidos por Leis. Cria-se assim um outro conceito, o de "legal", que em linhas gerais sempre concorda com o "moral", visto que as leis são escritas com base nos costumes. Em nosso exemplo, o da escravidão, a legislação não apenas aceitava a escravidão como também dispunha dos direitos dos senhores e estabelecia punições aos que auxiliavam a fuga dos escravos. Por isso, nessa época, a escravidão era "moral" e "legal".

Coisa diversa dos costumes, das leis e da moral vigente são os juízos de apreciação sobre valores concernentes à conduta humana para com os semelhantes. Tais valores, qualificados do ponto de vista do bem e do mal, formam um conjunto de juízos a que denominados "éticos".

Ética, assim, pode ser definida como o estudo dos juízos de apreciação referentes à conduta humana susceptíveis de qualificação do ponto de vista do bem e do mal. Exemplos claros de princípios éticos são conceitos de apenas ser lícito tirar a vida de um ser humano em casos de legítima defesa, ou mesmo o conhecido aforismo do "não façais aos outros o que não desejares que te façam".

Pode-se claramente perceber que nem tudo o que é "moral" ou "legal" é "ético". A escravidão, citada como exemplo, pode ter sido considerada como "moral", visto que fazia parte dos costumes aceitos pela sociedade. Era também "legal", visto que os códigos então vigentes a aceitavam e normatizavam. Nunca, porém, foi "ética".

Dentro dessa visão, importa ficar clara a mensagem de ser a ética independente dos costumes, da época e do grupo socio-econômico-cultural considerado. O que é hoje ético é o que sempre foi e sempre será ético. Não 
existem variações, tais como as observadas nos conceitos de "legal" e de "moral". Tais princípios são, por sua própria natureza, atemporais e universais, aplicando-se sempre em todos os casos de relacionamento entre seres humanos. Por isso mesmo, não existe uma "Ética Médica", conceito inadequado que vemos repetido para várias outras profissões, pois os princípios éticos básicos são sempre os mesmos. O que se quer significar, na verdade, é a aplicação dos princípios éticos ao comportamento desejável dos médi$\cos$, e não uma ética específica para uma determinada profissão. Por isso mesmo não escrevemos sobre a "Ética do Terapeuta Sexual", mas sim sobre os princípios éticos aplicados à essa atividade, motivo pelo qual o presente texto tem o título de "Aspectos éticos da terapia sexual".

O estudo dos princípios éticos, dentro dos conceitos que ora traçamos, sempre se constituiu em preocupação para os pesquisadores. Até onde se tem notícia, o primeiro documento a respeito do assunto foi o "Código de Hamurabi", um conjunto de normas que traçava punições, que hoje consideraríamos descabidas, aos que infringissem determinados princípios. $\mathrm{O}$ Código de Hamurabi, que ao que parece foi inspirado em um documento sumério ainda mais antigo, foi inscrito numa coluna ("stella") exibida ao público, e era fundamentalmente baseado no princípio do "olho por olho, dente por dente". Apesar de ser muito mais um conjunto de normas legais, é considerado como um precursor dos princípios éticos.

Segundo nossos conhecimentos históricos, o documento seguinte na cultura ocidental é constituído pelo chamado "Juramento de Hipócrates", atribuído ao fundador da célebre escola médica da Ilha de Cós, e que se constitui na base para o Código de Ética Médica ainda nos dias atuais. Sem dúvida contém muitos princípios que hoje consideraríamos anti-éticos, tais como a proposta de que o médico só deve instruir na arte seus próprios filhos e os filhos de seus colegas e amigos. Apesar disso, sem dúvida contém princípios elevados, no que diz respeito aos aspectos éticos da profissão médica.

Praticamente todos os filósofos clássicos se preocuparam, de uma forma ou de outra, com os conceitos éticos. O estudo da ética tem progredido acentuadamente nas últimas décadas, notadamente no que diz respeito a aspectos particulares, tais como o da ética aplicada à pesquisa e os conceitos éticos envolvidos nas diferentes formas de reprodução assistida, no que vem sendo denominado de "bio-ética". Quanto à ética aplicada à pesquisa, são documentos básicos para o estudo dessa faceta a Declaração de Nuremberg e suas sucedâneas (Genebra, Lisboa, Helsinque, Tóquio, Veneza e Hong-Kong), que estabelecem os mais importantes princípios a serem observados nos estudos envolvendo seres humanos. No Brasil, existe um órgão governamental que rege o assunto, a Comissão Nacional de Ética em Pesquisa (CONEP), ligada ao Conselho Nacional de Saúde, que edita uma publicação periódica, os "Cadernos de Ética em Pesquisa".

No que diz respeito à ética aplicada aos aspectos mais atuais dos processos de fertilização assistida, tem-se discutido ainda vários pontos, não 
havendo um consenso. O que fazer, por exemplo, dos embriões que não são aproveitados nos processos de fecundação? Como resolver, eticamente, os problemas advindos da fertilização assistida, quando resultam vários embriões viáveis intra-útero, aumentando o risco da prenhez? Quem decide, e como, quais os embriões que devem ser sacrificados (ou "reduzidos", num neologismo que não consegue esconder os problemas de tal decisão)? Na maioria desses pontos ainda não se tem um consenso, estando o assunto ainda aberto à discussão.

\section{2 - ÉTICA APLICADA À TERAPIA SEXUAL}

Vejamos agora, em linhas gerais, a aplicação de princípios éticos à atividade do terapeuta sexual. Podemos considerar o assunto em três vertentes principais, que dizem respeito aos aspectos éticos do relacionamento do profissional com sua clientela, ao relacionamento entre os terapeutas sexuais e outros profissionais e o relacionamento entre profissionais de um mesmo serviço.

\section{a) Relacionamento profissional-paciente}

\section{Organização do consultório}

$\mathrm{O}$ primeiro aspecto diz respeito à própria organização do consultório de médicos e psicólogos que se dedicam à Terapia Sexual. Claro que qualquer consultório de uma dessas atividades profissionais devem ser respeitados princípios gerais, tais como o do segredo profissional. No entanto, sendo a temática sexual considerada tão particular e sendo tão pouco publicamente explicitável, deve ela ser cercada de redobrado cuidado no que diz respeito à preservação do segredo profissional. Assim, a organização do consultório deve tornar claro esse cuidado.

$\mathrm{O}$ isolamento acústico das salas, a maneira de vestir-se do terapeuta e da própria secretária, o treino da secretária sobre a inconveniência de troca de informações entre clientes, os prontuários devidamente arquivados sem possibilidade de acesso de terceiros, o não atendimento de recados telefônicos durante a consulta e tantos outros itens devem ser cuidados nos mínimos detalhes para que nos asseguremos, até onde possa ir a humana certe$\mathrm{za}$, de garantirmos privacidade aos nossos clientes.

\section{A captação da clientela}

A clientela dos terapeutas sexuais é captada, como a de qualquer outro médico ou psicólogo, através da publicidade feita pelos próprios clientes, por meios de divulgação ou por outros profissionais ("referência").

A publicidade mais segura e mais ética é, sem dúvida, aquela feita por pacientes já tratados ou em tratamento. De fato, ninguém mais confiável 
para informações sobre a capacidade de um profissional do que alguém que foi exitosamente por ele tratado. No entanto, até que um terapeuta sexual tenha massa crítica de ex-pacientes capaz de se incumbir de divulgar sua capacidade entre eventuais futuros clientes, é necessário um certo tempo de atividade. Por isso a modalidade de captação de clientela através dos meios de comunicação e por referência de outros profissionais assume importância.

Nada há de errado com a divulgação das qualidades dos profissionais através dos meios de comunicação. O que pode se constituir (e freqüentemente se constitui) em atos anti-éticos é a forma como essa publicidade é feita. Anunciar que o profissional Fulano trata casos de Ejaculação Precoce, por exemplo, não tem nada de anti-ético; mas se o anúncio disser que o mesmo profissional cura sempre todos os casos, ou que usa de recursos secretos ou não aceitos pela comunidade científica como válidos, ou ainda que curou esta ou aquela personalidade conhecida, o anuncio sem dúvida será anti-ético. Na verdade não é a publicidade em si que se constitui em atentado aos princípios éticos, mas sim a forma como ela pode ser apresentada.

Note-se que, quando nos referimos à divulgação pelos meios de comunicação estamos nos referindo não apenas aos anúncios diretos, claramente pagos pelo profissional, mas também aquela feita em programas diversos, tais como os famigerados "programas de entrevistas" que se tem multiplicados em nossos meios de comunicação, onde um apresentador "expontaneamente" (na maioria das vezes mediante pagamento) convida e faz as perguntas desejadas ao entrevistado.

A divulgação das qualidades profissionais de um terapeuta sexual pode ainda ser feita por outros profissionais. Não é incomum que psicólogos e médicos de várias especialidades, por não se sentirem preparados para o tratamento de uma queixa de fundo sexual, encaminhem o paciente para um determinado terapeuta de sua confiança. Não há nada de anti-ético nessa eventualidade, desde que a referência do paciente seja feita pelo outro profissional por achar que realmente aquele determinado terapeuta sexual é competente. Infelizmente, temos visto indicações por motivos menos confessáveis, chegando mesmo até ao pagamento de percentuais à quem indica, num esquema absolutamente inaceitável do ponto de vista ético.

Em resumo, desejamos deixar clara nossa posição de não nos considerarmos contrários à divulgação de serviços, desde que essa divulgação corresponda à qualidades reais do terapeuta sexual, e não a venda de ilusões, infelizmente comuns nessa área. Assim, procedimentos diversos, até mesmo cirúrgicos, são anunciados como "milagrosos" por alguns maus profissionais, contrariando toda a lógica aceita pelo mundo científico e batendo de frente com princípios éticos elementares.

\section{$O$ contrato profissional paciente}

Prática a que os médicos em geral não estão habituados, a formulação clara de um contrato de direitos e deveres de ambas as partes é uma neces- 
sidade entre terapeutas sexuais e clientes. Isso ocorre por não ser o entendimento das questões relativas ao atendimento tão fácil como a princípio parece, especialmente por estar o paciente, na maioria das vezes, tomado de intensa angústia. Horários a serem cumpridos, valor ajustado, garantias de sigilo, faltas aos atendimentos, reposição de sessões de terapia, metas a serem alcançadas, valor e forma de pagamento do tratamento, enfim, um sem número de quesitos que envolvem um relacionamento claro e transparente, que devem ficar explicitados. O contrato não precisa obrigatoriamente ser redigido por escrito, embora isso seja o ideal. Mas ao menos verbalmente tais pontos devem ser claramente definidos, para que não pairem sombras sobre as questões afetas ao tratamento.

\section{Sigilo}

Embora implícito em todos os tipos de atendimentos médicos e psicológicos, o sigilo profissional deve ser claramente explicitado, dando-se plena e total garantia ao paciente de que suas queixas e declarações não serão comentadas com terceiros.

Faz exceção a essa norma a apresentação do caso, pelo terapeuta, em processos de supervisão, e nos casos de atendimento de um cliente no âmbito de uma instituição.

No que diz respeito ao processo de supervisão, deve ficar evidente ser a atividade de terapeuta um processo altamente desgastante, o que torna recomendável que ele se submeta a supervisão de um terapeuta mais experiente, que discutirá os casos e fará observações com o intuito de otimizar os atendimentos. O processo de supervisão, longe de ser um reconhecimento de incapacidade ou de imaturidade de um terapeuta, é um processo altamente desejável, visto que sua prática melhora a qualidade do atendimento. Por isso, quando da formulação do Contrato Terapêutico a que nos referimos no item anterior, é de fundamental importância que o paciente tenha conhecimento de que seu caso poderá ser discutido num processo de supervisão, sem que isso implique em quebra de segredo profissional, visto que os clientes não são identificados.

Situação diversa é o atendimento dentro de um esquema institucional, onde militam, além dos terapeutas sexuais, profissionais de outras áreas, tais como médicos e psicólogos. Evidentemente não haveria o sentido de atendimento multiprofissional se cada profissional guardasse apenas para si mesmo as informações obtidas. Assim, os pacientes devem estar cientes de que as informações prestadas durante um processo de terapia poderão eventualmente serem discutidas por exemplo com um médico, se isso for de importância para o tratamento. Longe de se constituir em quebra de sigilo, o processo é na verdade apenas uma extensão desse segredo. Em vez de ser apenas o terapeuta sexual o profissional obrigado a guardar sigilo sobre o caso, serão também os outros profissionais os cumpridores desse preceito. 
Os princípios básicos do sigilo profissional são aplicáveis tanto à terapia individual quanto às modalidades de atendimento grupal, em grupos abertos ou fechados, e no caso do atendimento de casais. Nesses atendimentos, todos os implicados ficam comprometidos a manter o sigilo

\section{Modalidades de relacionamento}

Do ponto de vista pessoal, o portador de um problema encontra-se fragilizado diante do terapeuta. Isso leva as vezes, infelizmente, a situações onde os profissionais de má formação ética possam tirar algum proveito, o que contraria frontalmente os mais comezinhos princípios do relacionamento e da ética profissional. Conhecem-se casos, para exemplificar, de "terapeutas" mal orientados e sexualmente imaturos que se propuseram como "remédio" para resolver problemas sexuais de clientes. Tal conduta, além de imoral e ilegal, é absolutamente anti-ética.

A proximidade até afetiva do paciente com o terapeuta, faz parte do processo de tratamento, dentro de um processo denominado de "transferência e contra-transferência". Esse relacionamento, se conduzido de forma inadequada pelo terapeuta, pode resultar em interesse afetivo-sexual do paciente pelo mesmo, o que é claramente nocivo para o tratamento, devendo ser combatido.

Embora não seja nosso tema, nunca é demais lembrar que um dos prérequisitos mais importantes na formação de um terapeuta sexual é a adequação sexual própria, condição indispensável para o sucesso de qualquer tratamento. Evidentemente, se o profissional não consegue lidar maduramente com sua própria sexualidade, será incapaz também de lidar com a sexualidade de sua clientela.

\section{Entrevistas para a imprensa leiga. Comunicações científicas}

Ainda que já tenhamos discorrido sobre a participação de profissionais em entrevistas, quando nos referimos ao processo de captação de clientela, nunca é demais realçar a necessidade da manutenção do sigilo profissional. Assim, por mais que a divulgação da lista de personalidades por ele atendidas trouxessem clientes a um terapeuta, tal divulgação é absolutamente anti-ética.

Mesmo quando da apresentação de casos em reuniões científicas, deve o profissional assegurar-se de não haver maneiras de que os pacientes sejam identificados pelas informações prestadas perante outros colegas. Por isso, além do nome, devem-se omitir, dependendo de cada caso, outras informações tais como a profissão, características físicas, etc., que possam levar a essa identificação.

\section{b) Relações interprofissionais}

Nas relações com outros profissionais devem vigir os mesmos princípios até aqui discutidos. 
Assim, mesmo para divulgar entre profissionais as atividades que exerce, o terapeuta sexual deve pautar-se pela discrição e pela veracidade, oferecendo seus serviços dentro de princípios de clareza e veracidade. Ostentar títulos que não tem, propor serviços para os quais não está devidamente capacitado, formular promessas de difícil cumprimento são, entre outras, atitudes anti-éticas.

O mesmo se diga no que se refere a comentários, ocasionais ou propositais, sobre a capacidade ou honestidade de outros profissionais ou concorrentes. Formular observações desairosas, ainda que indiretamente, é atitude altamente anti-ética, que resulta quase sempre em demérito para o próprio formulador da observação.

As relações entre terapeutas sexuais e outros profissionais, da mesma ou de outra área, devem se pautar por sinceridade e objetividade. Ninguém é obrigado a elogiar concorrentes; contra eles sacar comentários maldosos, entretanto, é absolutamente condenável, ainda mais quando fica evidente que o objetivo do comentário é enaltecer a pretensa superioridade de quem faz os comentários.

\section{c) Relações entre profissionais de um Serviço}

No que diz respeito às relações interdisciplinares não é raro que ainda encontremos, mesmo entre profissionais de formação adequada, conceitos e preconceitos descabidos sobre a importância ou falta de relevância dos serviços prestados por profissionais de outras áreas. É infelizmente freqüente que médicos sub-avaliem a capacidade profissional e de atuação de enfermeiros, por exemplo, ou que psicólogos pré-julguem outros profissionais, arrogando-se como únicos detentores dos conhecimentos sobre o psiquismo humano.

É óbvio que tal pre-julgamento é preconceituoso, visto que, dentro de cada área, qualquer profissional pode prestar serviços relevantes na busca da solução dos problemas dos pacientes, meta última de qualquer tipo de atendimento efetuado por profissionais da área da saúde.

Mesmo dentro de um mesmo ramo de saber, intradisciplinarmente, entretanto, dificuldade de relacionamento de caráter ético podem se manifestar. Não é incomum que, baseados em falsos princípios (antigüidade, por exemplo) um profissional julgue-se "dono da verdade". Aqui, como em qualquer outra área, todo cuidado é pouco, no que diz respeito à conduta ética. Não podemos e não devemos deixar de considerar que, além da possibilidade de estarmos errados no que diz respeito a um determinado pormenor, a defesa de nossas posições e opiniões deve ser sempre enfática, visto que nelas cremos, mas nunca ofensiva ou tentando levar ao demérito a opinião alheia.

Lembremo-nos de o sábio se mede pelas atitudes, e não apenas pela quantidade de conhecimentos. Temos assim analfabetos que são sábios e 
pós-graduados que não o são. Mais importante do que o saber é o que se faz com esse saber...

Toda e qualquer área profissional é respeitável, não havendo nesse sentido profissões mais ou menos respeitáveis ou nobilitantes. Assim, tentar diminuir a importância de alguém por não possuir tal ou qual diploma ou certificado pode ser uma atitude tola, além de contraproducente.

Devemos considerar sempre as opiniões de outros profissionais, tentando ver nelas não apenas má vontade para conosco ou mesmo intenções desonestas. É um princípio básico elementar de sabedoria aplicada saber ouvir e considerar outros pontos de vista, embora isso não signifique que devamos obrigatoriamente abrir mão de nossos princípios ou idéias.

Do ponto de vista de uma conduta eticamente elogiável é importante sim que defendamos nossos pontos de vista, mas sem que isso implique em desconsideração ou pré-julgamento de pontos de vista alheios.

\section{REFERÊNCIAS BIBLIOGRÁFICAS}

BRESCIANI, C. Personalismo e morale sessuale. Aspetti teologici e psicologici. Roma: Piemme, 1983.

CAFFARRA, C. Etica generale della sessualitá. Milano: Ares, 1992. . Sexualidad a luz de la antropologia y de la Biblia. Madrid: Rialp, 1991.

CANELLA, P. R. B. \& VITIELLO, N. Tratado de reprodução humana. Rio de Janeiro: Cultura Médica, 1996.

CARDOSO, E. R. G. A formação profissional do psicoterapeuta. São Paulo: Summus, 1985.

CAVALCANTI, R. e VITIELLO, N. Sexologia I. 2. ed. São Paulo: CEICH, 1997.

JEANNIERE, A. Antropologia sexual. Lisboa: Morais Editora, 1965.

MALDONADO, M. T. e CANELLA, P. R. B. A relação médico-paciente. São Paulo: Roca, 1987.

MANNOCCI, J. F.; RODRIGUES JR., O. M.; CONCEIÇÃO, I. S. C. e VITIELLO, N. Disfunções Sexuais: abordagem clínica e terapêutica. São Paulo: Fundo Editorial BYK, 1995.

MINICUCCI, A. Dinâmica de grupo. Teorias e sistemas. São Paulo: Atlas, 1982.

VERITATIS SPLENDOR. Sobre algumas questões fundamentais do ensinamento moral da Igreja. Carta Encíclica de João Paulo II, 1993.

VITIELLO, N. Sexualidade: quem educa o educador. São Paulo: Iglu, 1997.

VITIELLO, N.; OLIBONI, E. R. D.; DAUD, S. e YABUSAKI, E. T. Afinal, o que é terapia sexual? RBSH 9(1):15-7, 1998. 